\title{
Heritage Acculturation Is Associated with Contextual Factors at Four Different Levels of Proximity
}

\author{
Marina M. Doucerain \\ Université du Québec à Montréal
}

\begin{abstract}
What factors explain the extent to which members of cultural minorities maintain their heritage cultural engagement? Although this process, called heritage acculturation, has significant implications for adjustment, we know little about its antecedents. The present work sought to address two shortcomings of acculturation research: (a) the need to characterize antecedents of acculturation orientations and (b) the need to consider acculturation as a contextual phenomenon. Some studies have documented associations between acculturation and specific contextual variables (e.g., family socialization), but an important feature of this research was to examine the unique contribution of factors at multiple levels of proximity simultaneously. Specifically, this study considered intraindividual, home, social network, and neighborhood-level contextual correlates of heritage acculturation. The overarching hypothesis tested among multicultural university students in Canada $(n=271)$ was that people whose life contexts are more strongly imbued with heritage cultural influences would report greater heritage acculturation. Results fully supported this hypothesis. Greater heritage language competence, "parental" living arrangements, a more extensive heritage social network, and living in an ethnically denser neighborhood were all related to greater heritage cultural maintenance. Further, only heritage network extensiveness was negatively related to mainstream cultural engagement-attesting to the cultural specificity of these associations. These results suggest that none of the four contextual levels considered here was sufficient on its own to understand participants' heritage acculturation and that we need a holistic view of the person in her or his multiple contexts when studying acculturation.
\end{abstract}

Keywords: acculturation, immigration/migration, family/child rearing, environmental/population, group processes

\section{Introduction}

Hamid and Basir are both Iranian immigrants to Canada, now in their early 20s. Hamid volunteers at the local Iranian Saturday school, celebrates Nowruz (Persian new year), and generally has a strong sense of being Iranian. Basir, on the contrary, tends to see his Iranian cultural heritage as a burden and to resent being considered Iranian. What factors can explain the differences in how these two young men position themselves with respect to their heritage culture? Although this positioning, called heritage acculturation, has significant positive implications for adjustment (Nguyen \& Benet-Martínez, 2013), we know little about its antecedents (Sam \& Berry, 2010).

Only a few studies have examined the predictors of acculturation orientations, and they have mostly focused on

Corresponding Author:

Marina M. Doucerain, Department of Psychology, Université du Québec à Montréal, 100 Sherbrooke O., Montréal, Québec, Canada H3C 3P8. Email: doucerain.marina@uqam.ca intrapersonal influences, such as personality (Kosic, 2006). Yet, recent theories of acculturation adopt an ecological perspective (Ward \& Geeraert, 2016) and stress that acculturation is shaped by contextual influences at different levels, ranging from intrapersonal dispositions to family characteristics, to features of the larger society (Lopez-Class, Castro, \& Ramirez, 2011; Schachner, van de Vijver, \& Noack, 2017). Accordingly, this article considers the associations between heritage acculturation and variables indexing how strongly people's life contexts are imbued with their heritage culture.

\section{Conceptualizing Acculturation}

Psychological acculturation refers to changes in people's "cultural ways" - cultural behaviors, identities, and values-as a result of prolonged exposure to a cultural environment. In the dominant bidimensional framework of acculturation (Berry, 2005; Ryder, Alden, \& Paulhus, 2000), people like Hamid and Basir must negotiate in parallel issues of Iranian cultural engagement (heritage acculturation) and of 
Canadian cultural engagement (mainstream acculturation). ${ }^{1}$ Some researchers cross these two independent orientations to form four categories (integration, separation, assimilation, and marginalization; Berry, 1980, 1997), but measurement issues associated with this typological approach make dimensional approaches that consider heritage and mainstream acculturation separately preferable (Demes \& Geeraert, 2014; Rudmin \& Ahmadzadeh, 2001; Ward \& Kus, 2012).

Acculturation has important adjustment implications for people who juggle several cultures. A recent meta-analysis showed that greater maintenance of one's heritage culture and greater adoption of the mainstream culture are both associated with better sociocultural and psychological adjustment (Nguyen \& Benet-Martínez, 2013). Specifically, whereas mainstream acculturation may be more beneficial for sociocultural adjustment, heritage acculturation may be particularly crucial for psychological adjustment (Ward \& Kennedy, 1994; but see Ryder et al., 2000 for diverging results), especially in the face of discrimination (Branscombe, Schmitt, \& Harvey, 1999).

Despite the practical significance of heritage and mainstream acculturation, their antecedents have been relatively unexplored, as highlighted by Sam and Berry (2010) in a comprehensive review of acculturation research. In addition, much of acculturation research has focused on individuallevel variables, without taking into account the context within which this phenomenon takes place (Jurcik et al., 2014). As a step toward filling these gaps, this study focused on the contextual correlates of heritage acculturation, which typically receives less attention than mainstream acculturation, among multicultural university students.

University years typically correspond to young adulthood and to a transition to life outside of the parental home, a period that is particularly important for heritage acculturation. Indeed, ethnic identity development, whereby young people develop an attachment to their ethnic/heritage group and come to identify with it, occurs during those years (Phinney, 1990). As social life transitions more fully outside of the home, young people also increasingly need to negotiate their position with respect to their heritage culture on their own, with diminishing parental influences. These circumstances make university students an ideal population to examine connections between contextual factors and heritage acculturation.

\section{An Ecological Framework of Acculturation}

Researchers now widely acknowledge that acculturation is strongly tie to its multifaceted ecological context (ArendsTóth \& Van de Vijver, 2006; Bourhis, Moïse, Perreault, \& Senécal, 1997; Knight, Bernal, Garza, Cota, \& Ocampo, 1993; Lopez-Class et al., 2011; Motti-Stefanidi, Berry, Chryssochoou, Sam, \& Phinney, 2012; Ward, Fox, Wilson,
Stuart, \& Kus, 2010; Ward \& Geeraert, 2016). Beyond intraindividual characteristics (e.g., language proficiency or personality characteristics), contextual factors at different levels of analysis contribute to people's engagement with their cultural contexts. For example, Hamid's higher heritage acculturation, compared with Basir's, may be due not only to better proficiency in Farsi (intraindividual factor) but also to a tightly knit family that emphasizes Iranian traditions and to living in a neighborhood with a vibrant Iranian immigrant community (contextual factors). Different ecological perspectives emphasize different contexts. As Motti-Stefanidi and colleagues (2012) point out, whereas developmental psychologists tend to underscore the role of more microlevel contexts such as the family, social psychologists tend to focus on intergroup contexts and acculturation researchers on the influence of the broader cultural environment. Nevertheless, analogous to Bronfenbrenner's ecological systems theory, these ecological perspectives all picture the acculturating individual at the center of concentric circles representing more proximal (e.g., the family) to more distal (e.g., the larger society) contexts. Factors at four levels of proximity (described in more detail below) are considered here: intraindividual, home, social network, and neighborhood. The extant literature has documented associations between each contextual factor and heritage acculturation separately, but simultaneous examinations of these multifaceted factors are still scarce (Syed, Juang, \& Svensson, 2018). The present work seeks to address this gap. As a notable example of recent research in that direction, Schachner, van de Vijver, and Noack (2018) found that school, family, and ethnic group characteristics were all related to acculturation. In line with this research, the overarching hypothesis tested here is that navigating life contexts more strongly imbued with heritage cultural influences will be associated with greater heritage acculturation.

\section{Intraindividual Level}

Heritage language competence is one of the most crucial intraindividual factors contributing to the maintenance of one's heritage cultural engagement (LaFromboise, Coleman, $\&$ Gerton, 1993). This factor serves important sociocultural functions, allowing people to communicate with members of their heritage cultural group and to have access to cultural representations and resources (He, 2010). Heritage language competence is also an essential marker of heritage identity, allowing a person to be considered as "one of us" by members of the heritage group (Kvernmo \& Heyerdahl, 1996;

\footnotetext{
${ }^{1}$ Heritage versus mainstream is a simplistic dichotomy that does not just do justice to the cultural complexity of many migrants' and members of cultural minorities' lives, which are characterized by cultural hybridity and plurality. However, given that the present study does not focus on these issues, heritage versus mainstream labels are used as convenient proxies and are recognized as such.
} 
Nystad, Spein, Balto, \& Ingstad, 2017). For example, members of the Iranian-Canadian community might not consider Basir as a "real Iranian" because of his poor Farsi proficiency, which in turn would negatively impact his ability to maintain his heritage cultural engagement. Accordingly, in a sample of Asian Americans, greater heritage acculturation was associated with greater heritage language competence (Kang, 2006). These results echo other studies that established a positive association between heritage language competence and how people position themselves with respect to their heritage culture (Gibbons, 2004; Noels, Pon, \& Clément, 1996; Tse, 2000). For example, Clément's sociocontextual model, which has received a fair bit of empirical support over the years (Clément, Baker, \& MacIntyre, 2003; Noels et al., 1996), posits that language confidence predicts identification with the associated ethnolinguistic group (Clément, 1980). This model is also consistent with the present conceptualization of heritage language competence as an antecedent of heritage acculturation. Thus, at the intraindividual level, it is expected that greater heritage language competence will be associated with greater heritage acculturation (Hypothesis 1 [H1]).

\section{Home Level}

Young immigrants and members of cultural minorities acquire their heritage cultural knowledge primarily in the familial context, in contrast to mainstream youth who have access to mainstream cultural representations and practices in the larger society (Kim Park, 2007). Family socialization is key to the transmission of heritage cultural values (Knight et al., 2011) and youth identification with their heritage cultural group (Kim Park, 2007; Knight et al., 1993). Indeed, youth report greater heritage acculturation when living in familial contexts where the heritage culture is more predominant or promoted (Schachner, Van de Vijver, \& Noack, 2014, 2018; Umaña-Taylor, Alfaro, Bámaca, \& Guimond, 2009), and immigrant parents and older adults typically emphasize heritage cultural maintenance longer and more intensely than their children (Birman, 2006; Telzer, 2010). Accordingly, this study considers the role of living with one's parents (including extended family such as grandparents) versus living on one's own (including romantic partner and/or roommates), as an index of the extent to which heritage cultural influences permeate the home. It is expected that parental living arrangements, reflecting greater heritage influences, will be associated with greater heritage acculturation (Hypothesis 2 [H2]).

\section{Social Network Level}

Outside of the family, an immigrant's heritage social network is an essential agent of heritage socialization (Knight et al., 1993; Miller et al., 2006), as cultural knowledge is transmitted and maintained through social connections with other members of the heritage group (Wan \& Chew, 2013). These social connections can also foster cultural maintenance by encouraging identification with the heritage cultural group (Wan \& Chew, 2013). Several studies have shown that a more extensive heritage social network is associated with greater heritage acculturation. Among Croatian immigrants to Italy, participants who were embedded in a more predominantly Croatian (rather than Italian) social group at arrival reported greater Croatian cultural maintenance (Kosic, 2004). People who had more numerous conational ties and interactions (as a proxy for heritage social network size) also reported greater heritage acculturation and identification (Cao, Zhu, \& Meng, 2017; Neto, 2002; Ward \& Kennedy, 1993). In line with these results, it is expected that a larger heritage network will be positively associated with heritage acculturation (Hypothesis 3 [H3]).

\section{Neighborhood Level}

Beyond one's family and immediate social network, the cultural features of one's neighborhood can be tied to heritage acculturation (Lopez-Class et al., 2011). Although the relevant literature is limited, ethnic density - for example, the percentage of Iranian-Canadians in Hamid's or Basir's neighborhood - has emerged as a particularly promising community characteristic involved in acculturation processes (Jurcik, Ahmed, Yakobov, Solopieieva-Jurcikova, \& Ryder, 2013). As an index of heritage culture predominance in a person's local community, ethnic density can make heritage cultural products, practices, and knowledge more accessible and more salient in one's daily life, which may, in turn, support heritage acculturation. Indeed, Birman, Trickett, and Buchanan (2005) found that Russian adolescent immigrants to the United States who lived in an area with a higher concentration of Russian Americans reported greater Russian behavioral acculturation. A similar positive association between ethnic density and heritage acculturation was found among women from the former Soviet Union living in the United States (Miller et al., 2009). Accordingly, it is expected that greater ethnic density in one's neighborhood will be associated with greater heritage acculturation (Hypothesis 4 [H4]).

\section{The Present Study}

This study considers four different types of contextual correlates of heritage acculturation among multicultural university students in Canada: intraindividual, home, social network, and neighborhood levels. The overarching hypothesis tested here is that people whose life contexts are permeated more predominantly by heritage cultural influences $(\mathrm{H} 1$ : greater heritage language competence, $\mathrm{H} 2$ : parental living arrangements, H3: broader heritage social network, and H4: greater ethnic density in neighborhood) will report greater heritage acculturation. To further establish their culturally 
specific relation to acculturation processes, it is expected that none of these contextual variables will be associated with mainstream acculturation (Hypothesis 5 [H5]; adoption of mainstream cultural characteristics). In addition, given that this study was conducted in a multicultural sample and that heritage cultural maintenance differs across ethnic and cultural groups (Schachner et al., 2018), an index of cultural distance between mainstream and heritage cultural streams was included as a covariate.

Several studies have documented associations between acculturation and contextual influences at specific levels (e.g., family socialization), but the current work contributes to a minimal body of work that examines contextual factors at different levels of proximity simultaneously (e.g., Schachner et al., 2018). This approach allows us to take into account overlaps among contextual factors, and to test the hypothesis that they are each independently and uniquely associated with heritage acculturation. Following ecological theoretical perspectives on acculturation, contextual variables are conceptualized here as antecedents of cultural orientations (MottiStefanidi et al., 2012; Schachner et al., 2017), but it is important to note that the cross-sectional nature of the present research precludes any conclusions about causality.

\section{Method}

\section{Participants and Procedure}

Multicultural students attending an English-speaking university in Montreal, Quebec, Canada, were recruited to take part in a larger project on acculturation and adjustment (initial $N=313$ ). Given the language focus of some predictors considered here, only the 271 participants who reported a heritage language other than English or French (Montreal's two mainstream languages) were included (228 females, $\left.M_{\text {age }}=22.46 ; S D_{\text {age }}=3.35\right)$. Participants who were first-generation immigrants $(69 \%$ of the sample born outside of Canada) had lived in Canada for 10.11 years $(S D=$ 7.64) on average. Seventeen percent of those first-generation participants were international or exchange students. Participants reported a large variety of heritage cultural backgrounds, with none representing more than $15 \%$ of the sample. More specifically, $40 \%$ indicated a cultural background from Europe, 24\% from the Middle East or greater Arabia, 19\% from Asia, 15\% from Central or South America, and $2 \%$ from Sub-Saharan Africa. "Italian" was the most frequently nominated cultural background among secondgeneration participants, and "Colombian" and "Romanian" the most common ones among first-generation participants. Interested students signed up for the study through a participant pool platform. They answered questionnaires online and received course credit as compensation for their time. The study took about 90 min to complete was approved by the university's ethical review board.

\section{Measures}

\section{Heritage and Mainstream Acculturation}

The Quebec version of the Vancouver Index of Acculturation (VIA; Ryder et al., 2000) includes 30 items on a Likert-type scale ranging from $1=$ strongly disagree to $9=$ strongly agree. Ten triplets of items with mirror wording form three subscales assessing heritage acculturation (VIA$\mathrm{H} ; \alpha=.92)$, English-Canadian acculturation $(\alpha=.87)$, and French-Canadian acculturation $(\alpha=.88)$. Following usage in past research (e.g., Jurcik et al., 2015) and recommendation by the scale's first author, mainstream acculturation (VIA-M) was operationalized as the highest score between English-Canadian and French-Canadian scores (e.g., if a participant obtains a score of 7.5 for English-Canadian acculturation and 6 for French-Canadian acculturation, his VIA-M score will be 7.5). An example item is "I am comfortable working with people from my heritage cultural group." Past research has shown the VIA to be a valid and reliable acculturation self-report measure (Huynh, Howell, \& BenetMartínez, 2009; Kang, 2006; Ryder et al., 2000).

\section{Heritage Language Competence}

A six-item self-report measure (Doucerain, 2017) assessed participants' comfort in using their heritage language in linguistically demanding situations on a 7-point rating scale, ranging from $1=$ not comfortable at all to $7=$ as comfortable as a native speaker $(\alpha=.96)$. A sample situation was, "telling jokes to a group of [heritage language] speaking friends/colleagues."

\section{Living Arrangements}

Participants indicated with whom they live at home by selecting all applicable cohabitants among different options. Living with parents or extended family such as grandparents was recoded as "Parental," and living with romantic partner, children, roommates, siblings only, or alone was recoded as "Own." This variable served as an index of heritage culture predominance at the home level.

\section{Heritage Social Network Size}

Participants listed in how many different social contexts they routinely use their heritage language by answering the open-ended question "In what context(s) is [heritage language] the main language you use?" The number of social contexts nominated served as a proxy for the extensiveness of participants' heritage social network.

\section{Neighborhood Heritage Density}

Participants indicated what percentage of people in their neighborhood, in their estimation, are of the same heritage cultural background than themselves, using the following 
four levels: less than 10\%, between $11 \%$ and $50 \%$, between $51 \%$ and $75 \%$, and more than $75 \%$. Perceived heritage density has been found to be positively associated with objective density based on census data (Jurcik et al., 2015). This variable was dichotomized into less than $10 \%$ and more than $10 \%$ bins, to form reasonably even categories. It served as an index of heritage culture predominance at the neighborhood level.

\section{Cultural Distance}

Kogut and Singh's (1988) index served as a proxy for the distance between participants' heritage cultural background and the mainstream Canadian context. This index is based on Hofstede's cultural dimensions at the country level (Hofstede, Hofstede, \& Minkov, 2010), using the following formula:

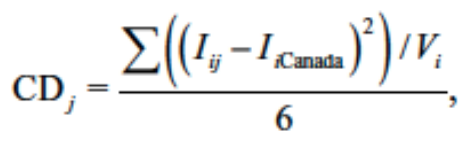

where $I_{\mathrm{ij}}$ represents the index for the $\mathrm{i}$ th cultural dimension (power distance, individualism, etc.) in jth nation, $V_{\mathrm{i}}$ is the variance of scores on the $i$ th dimension, and $\mathrm{CD}_{\mathrm{j}}$ is the cultural distance between $j$ th country and Canada. When cultural dimension scores were not available for a participant's heritage background, scores for the closest available country were used (e.g., West Africa for Mauritius or Arab countries for Oman).

\section{Analyses}

The hypotheses were tested using multiple regressions. Univariate outliers were winsorized, whereby extreme values outside three median absolute deviations around the median we brought within that interval (Leys, Klein, Bernard, \& Licata, 2013). No multivariate outliers (evaluated at a stringent level of $\mathrm{p}<.001$ ) were detected. Regarding missing data, data on age and on years lived in Canada were missing for $1 \%$ of the sample, and $10 \%$ of participants did not provide information for heritage language comfort. The assumption that data are missing completely at random (MCAR) was not met, $\chi^{2}(36)=126.50, p<.001$ for Little's test, but further analyses using logistic regressions on missing versus nonmissing values showed that data could be considered missing at random (MAR). Given that one variable had more than 5\% missing values, missing data were imputed with multiple imputation (with 30 imputations; Graham, Olchowski, \& Gilreath, 2007), using the R package Amelia (Honaker, King, \& Blackwell, 2011). Analyses then proceeded as planned. Results were pooled with the Barnard-Rubin adjusted degrees of freedom method (Barnard \& Rubin, 1999), using the R package mice (Buuren \& van Groothuis- Oudshoorn,
2011). Regression diagnostics showed that statistical assumptions of linearity, normality, and homoscedasticity were respected and that multicollinearity was not an issue (variance inflation factor $<2.50$ for all variables).

\section{Results}

\section{Descriptive Results}

On average, participants reported fairly high levels of heritage $(M=7.13, S D=1.63)$ and mainstream acculturation $(M$ $=7.25, S D=1.22$ ), as indexed by VIA-H and VIA-M scores, respectively. They felt quite comfortable using their heritage language $(M=5.37, S D=1.74)$, which they routinely used in 1.58 social contexts on average $(S D=1.01)$. Concerning living arrangements, $60 \%$ of participants lived in a "parental" home environment. A similar proportion (62\%) reported living in an area where less than $10 \%$ of people were of the same heritage cultural background as themselves. Finally, cultural distance ranged between 0.26 and 5.12, with an average value of $2.02(S D=0.98)$. Table 1 presents zero-order correlations among the numerical study variables. As preliminary support for our hypotheses, heritage language comfort and social network were positively associated with heritage cultural maintenance (VIA-H), but not with mainstream cultural adoption (VIA-M). Heritage acculturation was also negatively and significantly related to cultural distance, highlighting the importance of controlling for this variable.

\section{Hypothesis Testing}

As shown in Table 1, there was a statistically significant positive association between heritage and mainstream VIA scores. To take into account this significant amount of shared variance, outcome variables were residualized: VIA$\mathrm{H}$ scores were residualized on VIA-M scores and vice versa (see Doucerain, Varnaamkhaasti, Segalowitz, \& Ryder, 2015 for a similar approach). This procedure ensures that regression results, presented in Table 2, reflect specific associations between contextual variables and cultural orientations. Predictors were entered hierarchically, with covariates (age, sex, generation, years lived in Canada, and cultural distance index) in a first step, and heritage contextual variables in a second step.

Consistent with $\mathrm{H} 1$ to $\mathrm{H} 4$, variables indexing stronger heritage cultural influences in participants' contexts were statistically significantly associated with greater heritage acculturation, as measured by VIA-H scores. Specifically, participants who felt more comfortable using their heritage language (H1: $\beta=.31, p<.001,95 \%$ confidence interval (CI) $=[0.18,0.45])$, who lived in a "parental" setup (H2: $\beta=.30$, $p=.03,95 \% \mathrm{CI}=[0.03,0.56])$, who had a more extensive heritage social network (indexed by a proxy variable; $\mathrm{H} 3: \beta$ $=.18, p=.004,95 \% \mathrm{CI}=[0.06,0.29])$, and who lived in 
neighborhoods with more people of the same heritage cultural origin $(\mathrm{H} 4: \beta=.25, p=.029,95 \% \mathrm{CI}=[0.03,0.47])$ reported statistically significantly greater heritage acculturation. Together, the introduction of these contextual

variables accounted for $17 \%$ additional variance in VIA-H scores (from $R^{2}=.09$ to $R^{2}=.26$ ), which was a substantial and statistically significant improvement.

Conversely, and mostly supporting H5, only one of those contextual variables was statistically significantly related to mainstream acculturation (VIA-M scores). Specifically, participants with a more extensive heritage social network also reported less mainstream cultural adoption $(\beta=-16, p=.01$, $95 \% \mathrm{CI}=[-0.28,-0.03])$. The introduction of contextual variables did not statistically significantly improve the prediction of VIA-M scores. The total variance accounted for in VIA-M scores was $19 \%$ (16\% in the first step).

In terms of covariates, a larger number of years lived in Canada was statistically associated with greater mainstream cultural adoption $(\beta=.46, p<.001,95 \% \mathrm{CI}=[0.29,0.62])$ and lower heritage cultural maintenance $\beta=-.25, p=.002$, $95 \% \mathrm{CI}=[-0.41,-0.09])$. However, second-generation immigrants reported greater heritage acculturation $(\beta=.47, p$ $=.004,95 \% \mathrm{CI}=[0.15,0.79])$ and lower mainstream acculturation than first-generation immigrants $(\beta=-.59, p=.001$, $95 \% \mathrm{CI}=[-0.92,-0.25])$. Finally, greater cultural distance, as measured by Kogut and Singh's (1988) index, was related to significantly lower heritage acculturation $(\beta=-.17, p=$ $.003,95 \% \mathrm{CI}=[-0.28,-0.06])$.

\section{Discussion}

The present study tested the overarching hypothesis that living in contexts more strongly influenced by one's heritage culture would be associated with greater heritage acculturation. This hypothesis was fully supported: greater heritage language competence, "parental" living arrangements, a more extensive heritage social network, and living in an ethnically denser neighborhood were all related to greater heritage cultural maintenance. Furthermore, only heritage social network extensiveness was associated (negatively) with mainstream cultural engagement - attesting to the cultural specificity of these associations.

The finding that "parental" living arrangements were positively associated with heritage acculturation is similar to results from Schachner and colleagues (2014) and UmañaTaylor and colleagues (2009), obtained in Germany and the United States, respectively. This suggests that for young people, the family context may be closely tied to issues of heritage maintenance regardless of the wider sociopolitical immigration context, which is very different in all three countries. Another aspect is noteworthy. Whereas these two past studies assessed specific characteristics of the family environment (e.g., importance of religion at home or family socialization scale), we measured the simple fact of living in a parental home, rather than the family's "heritage flavor." According to our results, the mere daily presence of parental figures may be sufficient to foster young adults' heritage acculturation, independently of how actively these parental figures promote heritage cultural maintenance. Alternatively, it is also possible that those seeking to minimize their heritage cultural engagement prefer living on their own, or that parents for whom heritage maintenance is a more central concern are reluctant to see their adult children leave the family home. This research did not allow us to disentangle these competing explanations, but the results point to the importance of parental presence in issues of heritage cultural maintenance.

The positive association between perceived ethnic density and heritage acculturation also complements the existing literature in interesting ways. Birman et al. (2005) and Miller and colleagues (2009) both also found a positive association in the United States, but they relied on an objective, censusbased measure of ethnic density. In contrast, Jurcik and colleagues (Jurcik et al., 2015; Jurcik et al., 2013) used a subjective measure of ethnic density and did not detect any association with heritage acculturation in Canada (although their subjective measure correlated with an objective indicator of ethnic density). Instead, they found that subjective perceptions of ethnic density interacted with heritage acculturation in the prediction of psychological adjustment. Our results suggest that both objective and subjective ethnic density may be associated with heritage acculturation, in line with Syed and colleagues' (2018) theoretical work. However, detecting this association with subjective indices may depend on measurement formats. Indeed, whereas Jurcik and colleagues asked participants to estimate how many people from their own ethnic group live in their neighborhood using a 5-point scale ranging from $1=$ none or hardly any to $5=$ almost all or all of the neighborhood, we provided categories with specific percentages, such as less than $10 \%$ or between $51 \%$ and $75 \%$. The latter format is more closely aligned with objective density metrics and may leave less room for individual interpretation regarding what constitutes "a lot" or "a little." On the contrary, a percentage format may be less ideally suited to tap into migrants' subjective perceptions of relative group representation in their immediate environment (Syed et al., 2018).

The extensiveness of one's heritage language network was positively associated with heritage acculturation, which is in keeping with past research (Cao et al., 2017; Kosic, 2004; Neto, 2002; Ward \& Kennedy, 1993). Interestingly, it was the only contextual variable that was also associated negatively with mainstream acculturation. Two explanations may account for these results. First, social network composition may be more susceptible to zero-sum cultural effects than other contextual variables, in the sense that interacting with people from one's heritage background in numerous and var- 


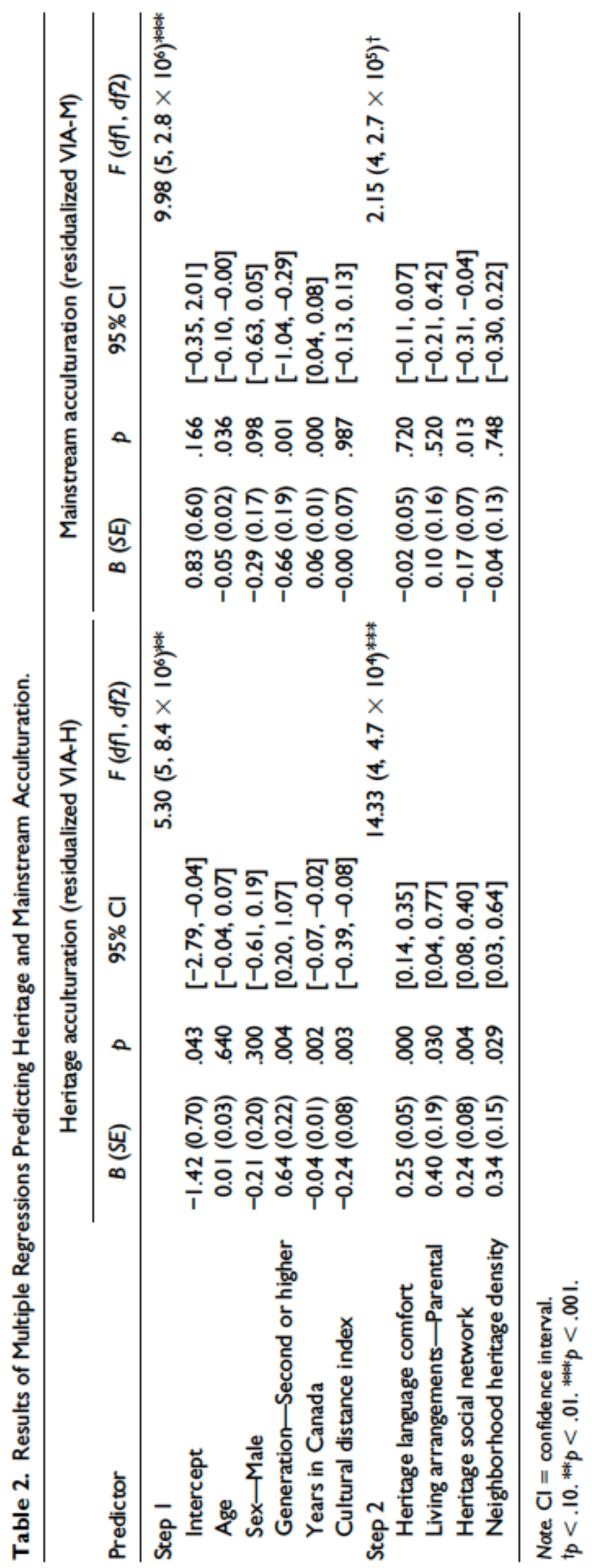


Table 1

Bivariate Correlations Among Numerical Study Variables.

\begin{tabular}{|c|c|c|c|c|c|c|}
\hline Variables & $(1)$ & $(2)$ & (3) & $(4)$ & $(5)$ & $(6)$ \\
\hline (1) Age & - & & & & & \\
\hline (2) Years in Canada & .12 & & & & & \\
\hline (3) Cultural distance index & .04 & $-.18^{* *}$ & & & & \\
\hline (4) Heritage language comfort & .10 & $-.40^{* * *}$ & $.14^{*}$ & & & \\
\hline (5) Heritage language network & -.01 & $-.19^{* *}$ & .02 & $.42^{* * *}$ & & \\
\hline (6) Heritage acculturation (VIA-H) & $-.12^{*}$ & -.06 & $-.16^{* *}$ & $.28^{* * *}$ & $.24^{* * *}$ & \\
\hline (7) Mainstream acculturation (VIA-M) & -.10 & $.27^{* * *}$ & -.07 & -.06 & -.10 & $.37^{* * *}$ \\
\hline
\end{tabular}

Note. VIA = Vancouver Index of Acculturation

$* p<.05 . * * p<.01 . * * * p<.001$.

ied settings may entail fewer interactions with people from the mainstream cultural stream. In turn, fewer mainstream interactions may be tied to lower mainstream acculturation. A second explanation concerns social network dynamics. Using one's heritage language in many daily settings is likely to index a tight heritage network structure, which, according to social network theorists, constrains people's social roles and limits their opportunities to explore new ideas (Burt, 1995). As such, a tight heritage network may be associated with less freedom to adopt mainstream cultural behaviors, values, or identities.

Regarding covariates, past research documented a negative zero-order correlation between perceived cultural distance and heritage acculturation (Schachner et al., 2018). The present results replicated this finding with a different index of cultural distance, based on country-level cultural dimension data, suggesting that this association holds across a range of measurement formats. A possible explanation is that maintaining cultural practices and traditions that are very different from that of the mainstream cultural context is more difficult than in the case of more similar heritage cultural backgrounds. Over time, struggles resulting from negotiating these more massive cultural gaps may compel people to gradually relinquish their cultural heritage.

The finding that more time lived in Canada was related to greater mainstream acculturation and lower heritage acculturation also replicated past results (Ryder et al., 2000). The converse finding that compared with first-generation participants, second-generation participants reported greater heritage acculturation and lower mainstream acculturation was more surprising and contradicted past research (Tonsing, 2014). The local context of the study may help explain these results. Montreal is a highly multicultural city, where cultural diversity is typically embraced and valued, especially in the university where participants were recruited. In such a context, maintaining one's heritage cultural characteristics is likely to be a source of positive self-differentiation. For firstgeneration participants, heritage affiliation and characteristics may be taken for granted, guaranteed by one's foreign birth. For second-generation participants, however, main- taining one's heritage distinctiveness may require more personal commitment and efforts, hence their higher heritage acculturation scores on average. In other words, the positive cultural currency of being a hyphenated Canadian in the context where the study took place may explain the current findings.

In summary, the results were consistent with theoretical arguments that acculturation is a contextual phenomenon, tied to factors at many different levels (Kim Park, 2007; Ward $\&$ Geeraert, 2016). Despite these theoretical arguments, the studies that do consider contextual influences in acculturation often focus on a single level, such family socialization (Umaña-Taylor et al., 2009) or ethnic density (Birman et al., 2005). Showing that all contextual levels act cumulatively and that each account for unique variance in heritage acculturation was a strength of this study. In other words, none of the four levels considered here was sufficient on its own to understand participants' heritage acculturation. The present results suggest that to do so, we need a holistic view of the person in her multiple contexts as a single dynamic multilevel system: "an information network instantiated in neuronal pathways, cognitive schemata, human relationships, culturally-mediated tools, global telecommunications, corporations, political actors, health care systems, and so on," where levels "cannot be understood in isolation from one another" (Ryder, Ban, \& Chentsova-Dutton, 2011, p. 965). This holistic, contextual view is relevant and vital beyond acculturation, and recent theoretical perspectives underscore the need to consider the role of socioecological factors in all psychological processes (Oishi \& Graham, 2010).

\section{Limitations and Future Directions}

Considering the independent contribution of several contextual variables simultaneously was a strength of this study, but several limitations should also be noted. First, the sample was clearly imbalanced in terms of participants' sex. The predominance of females may have affected average levels of heritage maintenance, as women tend to relinquish heritage characteristics less than men (Ward, 2001), potentially 
because of traditional gender roles tied to cultural transmission among women. Another limitation concerns the lack of information about cohabitants' cultural background, in the case of participants who lived outside of a parental home. It is entirely possible that living with roommates from the same heritage cultural background might be associated with a more positive heritage orientation.

Furthermore, this study included more than one contextual factor, but it still did not include the whole gamut of contexts. Biological (micro end of the spectrum) and larger sociocultural contextual influences (macro end of the spectrum) were unfortunately lacking. Past research suggests that both of these levels may also be relevant in understanding a person's acculturation. At the micro end of the spectrum, international students who arrived in the country with greater respiratory sinus arrhythmia (RSA) - a physiological index of individual differences in social engagement capacities-adopted the mainstream culture faster than those with lesser RSA (Doucerain, Deschênes, Aubé, Ryder, \& Gouin, 2016). At the macro end of the spectrum, the extent to which second-generation Turkish immigrants maintained their heritage religious engagement depended on in which European city they lived, reflecting different levels of institutional accommodation of Islam (Fleischmann \& Phalet, 2012). Building on the present conclusion that contextual variables are necessary to understand heritage acculturation, future research should attempt to consider the whole spectrum of microlevel to macrolevel contextual influences.

In the present research, each contextual level was unfortunately characterized using a single-and fairly simplistic-index. Syed and colleagues (2018) proposed that ethnic/racial settings can be characterized in terms of perspective (subjective vs. objective apprehension of setting), differentiation (how groups are defined in setting), heterogeneity (range of groups in setting), and proximity (closeness of setting to person). All dimensions may be relevant for acculturation, and this theoretical framework could help inform future characterizations of migrants' cultural contexts.

The cross-sectional design of the current study was also an explicit clear limitation of the current work. The conceptualization of contextual variables as antecedents of heritage acculturation was grounded in ecological theoretical perspectives of acculturation, but a reverse direction of effects cannot be ruled out. It is possible that participants with a stronger heritage orientation decided to stay in the parental home longer, actively worked toward developing their heritage language network, or decided to live in an ethnically denser neighborhood. Rather than unidirectional links, it is more likely that person and context mutually influence one another (Motti- Stefanidi et al., 2012), through feedback loops repeated over time (Doucerain, Deschênes, Gouin, Amiot, \& Ryder, 2017; Schachner et al., 2017). A context imbued with heritage cultural influences may foster a person's heritage orientation, which may, in turn, compel her to seek contexts with more heritage resources. Future longitudinal research should test this idea, which was beyond the scope of this study.

Adopting an ecological perspective, this study contributed to a body of work that examines contextual aspects of acculturation. Research in that direction is growing and promising, but several questions still need to be answered. First, what is the relative predictive ability of the different contextual factors? Knowing what contextual factors are most closely tied to acculturation would be essential for the design of effective interventions aimed at supporting people's acculturation. One possibility is that contextual associations decrease in strength as they become more distal: that is, intraindividual factors may be most essential and variables at the larger sociocultural level least important (Schachner et al., 2017).

A second question concerns the specific mechanisms underlying contextual associations. For example, how exactly is ethnic density related to heritage acculturation? By strengthening local social norms to maintain heritage cultural engagement? By providing greater cultural resources and opportunities for social interactions with people of the same cultural background? By making heritage cultural products and artifacts more salient in the local built environment (e.g., ethnic shops, heritage language signs)? These questions are closely related to efforts to understand the day-to-day microlevel mechanisms of cultural transmission (Kashima, 2008), which could serve as starting points for research in that direction.

A third question, also identified by Schachner and colleagues (2017; and discussed by Jurcik et al., 2015), concerns interactions among contexts at different levels. Considering the acculturating person in context as a single multilevel dynamic system (Ryder et al., 2011) suggests that contextual factors may not act in a simply additive fashion. For example, features of the broader sociocultural context such as immigration ideologies (Bourhis et al., 1997) may constrain the type of social networks that a migrant can build in the new country, in line with the suggestion that more macrolevel influences permeate more proximal contexts (Motti-Stefanidi et al., 2012). Similarly, family ethnic socialization's association with heritage acculturation may be dampened by young people's social ties with members of the mainstream cultural group. Understanding how contextual influences on acculturation at different levels influence one another, and constrain and afford one another, may benefit from borrowing concepts and methods from the field of nonlinear dynamical systems, as suggested by Vallacher, Read, and Nowak (2002) in the case of social psychological phenomena.

A final question pertains to developmental aspects of acculturation, given that associations between contextual factors and acculturation are likely to change across the lifes- 
pan. Existing theoretical frameworks address adolescence (Motti-Stefanidi et al., 2012; Schachner et al., 2017), but we know little about later life periods. For example, the distinction between "parental" versus "non-parental" living arrangements is relevant for university students, but likely won't be a decade later. Beyond university years, having a first child may also represent a significant milestone for heritage acculturation. Decisions such as choosing, say, Azadeh versus Allison as a baby name (or selecting a Farsi-speaking versus English-speaking day care reflect parents' heritage acculturation preferences (Gerhards \& Hans, 2009) and influence, in turn, the type of cultural environment that the family will experience daily. Retirement may be another important period, as immigrants negotiate whether to stay in their country of adoption or to return to their country of origin (Aguilera, 2004). Future work should map out trajectories of associations between acculturation and contextual variables across the lifespan.

Addressing these four sets of issues will help draw up a comprehensive account of acculturation as a contextual phenomenon across multiple levels and the lifespan. Given the implications of heritage and mainstream acculturation for people's adjustment and well-being, such an account is necessary if we want to support members of cultural minorities through their acculturation process adequately and in a holistic fashion. Meanwhile, this study contributed to an emerging body of work on contextual influences in acculturation by examining the unique contribution of contextual factors at four different levels of proximity (intraindividual, home, social network, and neighborhood) and by showing that people whose life contexts are more predominantly imbued by heritage cultural influences report greater heritage acculturation.

\section{Declaration of Conflicting Interests}

The author(s) declared no potential conflicts of interest with respect to the research, authorship, and/or publication of this article.

\section{Funding}

The author(s) disclosed receipt of the following financial support for the research, authorship, and/or publication of this article: This research was supported by a doctoral research scholarship from the Fonds de Recherche du Québec-Société et Culture to the author.

\section{ORCID iD}

Marina M. Doucerain https://orcid.org/ 0000-0003-0479-6141

\section{References}

Aguilera, M. B. (2004). Deciding where to retire: Intended retirement location choices of formerly undocumented Mexican migrants. Social Science Quarterly, 85, 340-360. doi:10.1111/j.0038-4941.2004.08502008.x

Arends-Tóth, J., \& Van de Vijver, F. J. R. (2006). Issues in the conceptualization and assessment of acculturation. In M. H. Bornstein \& L. R. Cote (Eds.), Acculturation and parent-child relationships: Measurement and development (pp. 33-62). Mahwah, NJ: Lawrence Erlbaum.

Barnard, J., \& Rubin, D. B. (1999). Small-sample degrees of freedom with multiple imputation. Biometrika, 86, 948-955.

Berry, J. W. (1980). Acculturation as varieties of adaptation. In A. M. Padilla (Ed.), Acculturation: Theory, models and some new findings (pp. 9-25). Boulder, $\mathrm{CO}$ : Westview.

Berry, J. W. (1997). Immigration, acculturation, and adaptation. Applied Psychology, 46, 5-34. doi:10.1111/j.14640597.1997.tb01087.x

Berry, J. W. (2005). Acculturation: Living successfully in two cultures. International Journal of Intercultural Relations, 29, 697-712. doi:10.1016/j.ijintrel.2005.07.013

Birman, D. (2006). Acculturation gap and family adjustment: Findings with Soviet Jewish refugees in the United States and implications for measurement. Journal of Cross-Cultural Psychology, 37, 568-589. doi:10.1177/0022022106290479

Birman, D., Trickett, E., \& Buchanan, R. M. (2005). A tale of two cities: Replication of a study on the acculturation and adaptation of immigrant adolescents from the former Soviet Union in a different community context. American Journal of Community Psychology, 35, 83-101. doi:10.1007/s10464- 005-1891-y

Bourhis, R. Y., Moïse, L. C., Perreault, S., \& Senécal, S. (1997). Towards an interactive acculturation model: A social psychological approach. International Journal of Psychology, 32, 369-386. doi:10.1080/002075997400629

Branscombe, N. R., Schmitt, M. T., \& Harvey, R. D. (1999). Perceiving pervasive discrimination among African Americans: Implications for group identification and wellbeing. Journal of Personality and Social Psychology, 77, 135-149. doi:10.1037/0022-3514.77.1.135

Burt, R. (1995). Structural holes: The social structure of competition. Cambridge, MA: Harvard University Press.

Buuren, S., \& van Groothuis-Oudshoorn, K. (2011). mice: Multivariate imputation by chained equations in $\mathrm{R}$. Journal of Statistical Software, 45(3), 1-67.

Cao, C., Zhu, C., \& Meng, Q. (2017). Predicting Chinese international students' acculturation strategies from sociodemographic variables and social ties. Asian Journal of Social Psychology, 20, 85-96. doi:10.1111/ajsp.12171

Cila, J., \& Lalonde, R. N. (2015, June). Cultural influences on baby-naming in a multicultural society. Paper pre- 
sented at the annual convention of the Canadian Psychological Association, Ottawa, Ontario, Canada.

Clément, R. (1980). Ethnicity, contact and communicative competence in a second language. In H. Giles, W. P. Robinson, \& P. M. Smith (Eds.), Language: Social psychological perspectives (pp. 147-154). Oxford, UK: Pergamon.

Clément, R., Baker, S. C., \& MacIntyre, P. D. (2003). Willingness to communicate in a second language: The effects of context, norms, and vitality. Journal of Language and Social Psychology, 22, 190-209. doi:10.1177/0261927X03022002003

Demes, K. A., \& Geeraert, N. (2014). Measures matter: Scales for adaptation, cultural distance, and acculturation orientation revisited. Journal of Cross-Cultural Psychology, 45, 91-109. doi:10.1177/0022022113487590

Doucerain, M. M. (in press). L2 experience mediates the relation between mainstream acculturation orientation and self-assessed L2 competence among migrants. Applied Linguistics. doi:10.1093/applin/amx036

Doucerain, M. M., Deschênes, S. S., Aubé, K., Ryder, A. G., \& Gouin, J.-P. (2016). Respiratory sinus arrhythmia is prospectively associated with early trajectories of acculturation among new international students. Journal of Cross-Cultural Psychology, 47, 421-440. doi:10.1177/0022022115624015

Doucerain, M. M., Deschênes, S. S., Gouin, J.-P., Amiot, C. E., \& Ryder, A. G. (2017). Initial mainstream cultural orientations predict early social participation in the mainstream cultural group. Personality and Social Psychology Bulletin, 43, 245-258. doi:10.1177/0146167216679642

Doucerain, M. M., Varnaamkhaasti, R. S., Segalowitz, N., \& Ryder, A. G. (2015). Second language social networks and communication-related acculturative stress: The role of interconnectedness. Frontiers in Psychology, 6, 1111. doi:10.3389/fpsyg.2015.01111

Fleischmann, F., \& Phalet, K. (2012). Integration and religiosity among the Turkish second generation in Europe: A comparative analysis across four capital cities. Ethnic and Racial Studies, 35, 320-341. doi: 10.1080/01419870.2011.579138

Gerhards, J., \& Hans, S. (2009). From Hasan to Herbert: Name-giving patterns of immigrant parents between acculturation and ethnic maintenance. American Journal of Sociology, 114, 1102-1128. doi:10.1086/595944

Gibbons, D. E. (2004). Friendship and advice networks in the context of changing professional values. Administrative Science Quarterly, 49, 238-262. doi:10.2307/4131473

Graham, J. W., Olchowski, A. E., \& Gilreath, T. D. (2007). How many imputations are really needed? Some practical clarifications of multiple imputation theory. Prevention Science, 8, 206-213. doi:10.1007/s11121-007-0070-9

He, A. W. (2010). The heart of heritage: Sociocultural dimensions of heritage language learning.
Annual Review of Applied Linguistics, 30, 66-82. doi:10.1017/S0267190510000073

Hofstede, G., Hofstede, G. J., \& Minkov, M. (2010). Cultures and organizations: Software of the mind (3rd ed.). New York, NY: McGraw-Hill.

Honaker, J., King, G., \& Blackwell, M. (2011). Amelia II: A program for missing data. Journal of Statistical Software, 45(7), 1-47.

Huynh, Q.-L., Howell, R. T., \& Benet-Martínez, V. (2009). Reliability of bidimensional acculturation scores: A meta-analysis. Journal of Cross-Cultural Psychology, 40, 256-274. doi:10.1177/0022022108328919

Jurcik, T., Ahmed, R., Yakobov, E., SolopieievaJurcikova, I., \& Ryder, A. G. (2013). Understanding the role of ethnic density effect: Issues of acculturation, discrimination and social support. Journal of Community Psychology, 41, 662-678. doi:10.1002/jcop.21563

Jurcik, T., Yakobov, E., Ahmed, R., SolopieievaJurcikova, I., Sunohara, M., \& Ryder, A. (2014). Social ecology and the recontextualization of acculturation: Exploring the psychological role of ethnic density. In J. Merton (Ed.), Acculturation: Psychology, processes and global perspectives (pp. 87-114). New York, NY: Nova.

Jurcik, T., Yakobov, E., Solopieieva-Jurcikova, L., Ahmed, R., Sunohara, M., \& Ryder, A. G. (2015). Unraveling ethnic density effects, acculturation, and adjustment: The case of Russian-speaking immigrants from the Former Soviet Union. Journal of Community Psychology, 43, 628-648. doi:10.1002/jcop.21708

Kang, S. (2006). Measurement of acculturation, scale formats, and language competence: Their implications for adjustment. Journal of Cross-Cultural Psychology, 37, 669-693. doi:10.1177/0022022106292077

Kashima, Y. (2008). A social psychology of cultural dynamics: Examining how cultures are formed, maintained, and transformed. Social and Personality Psychology Compass, 2, 107-120. doi:10.1111/j.1751-9004.2007.00063.x

Kim Park, I. J. (2007). Enculturation of Korean American adolescents within familial and cultural contexts: The mediating role of ethnic identity. Family Relations, 56, 403-412. doi:10.1111/j.1741-3729.2007.00469.x

Knight, G. P., Berkel, C., Umaña-Taylor, A. J., Gonzales, N. A., Ettekal, I., Jaconis, M., \& Boyd, B. M. (2011). The familial socialization of culturally related values in Mexican American families. Journal of Marriage and the Family, 73, 913-925. doi:10.1111/j.1741-3737.2011.00856.x

Knight, G. P., Bernal, M. E., Garza, C. A., Cota, M. K., \& Ocampo, K. A. (1993). Family socialization and the ethnic identity of Mexican-American children. Journal of Cross-Cultural Psychology, 24, 99-114. doi:10.1177/0022022193241007

Kogut, B., \& Singh, H. (1988). The effect of national culture on the choice of entry mode. Jour- 
nal of International Business Studies, 19, 411-432. doi:10.1057/palgrave.jibs.8490394

Kosic, A. (2004). Acculturation strategies, coping process and acculturative stress. Scandinavian Journal of Psychology, 45, 269-278. doi:10.1111/j.1467-9450.2004.00405.x

Kosic, A. (2006). Personality and individual factors in acculturation. In D. L. Sam \& J. W. Berry (Eds.), Cambridge handbook of acculturation psychology (pp. 113-128). Cambridge, UK: Cambridge University Press.

Kvernmo, S., \& Heyerdahl, S. (1996). Ethnic identity in aboriginal Sami adolescents: The impact of the family and the ethnic community context. Journal of Adolescence, 19, 453-463. doi:10.1006/jado.1996.0043

LaFromboise, T., Coleman, H. L., \& Gerton, J. (1993). Psychological impact of biculturalism: Evidence and theory. Psychological Bulletin, 114, 395-412. doi:10.1037/00332909.114.3.395

Leys, C., Klein, O., Bernard, P., \& Licata, L. (2013). Detecting outliers: Do not use standard deviation around the mean, use absolute deviation around the median. Journal of Experimental Social Psychology, 49, 764-766. doi:10.1016/j.jesp.2013.03.013

Lopez-Class, M., Castro, F. G., \& Ramirez, A. G. (2011). Conceptions of acculturation: A review and statement of critical issues. Social Science $\mathcal{E}$ Medicine, 72, 1555-1562. doi:10.1016/j.socscimed.2011.03.011

Miller, A. M., Birman, D., Zenk, S., Wang, E., Sorokin, O., \& Connor, J. (2009). Neighborhood immigrant concentration, acculturation, and cultural alienation in former Soviet immigrant women. Journal of Community Psychology, 37, 88-105. doi:10.1002/jcop.20272

Miller, A. M., Sorokin, O., Wang, E., Feetham, S., Choi, M., \& Wilbur, J. (2006). Acculturation, social alienation, and depressed mood in midlife women from the former Soviet Union. Research in Nursing $\mathcal{E}$ Health, 29, 134-146. doi:10.1002/nur.20125

Motti-Stefanidi, F., Berry, J. W., Chryssochoou, X., Sam, D. L., \& Phinney, J. S. (2012). Positive youth adaptation in context. Developmental, acculturation and social psychological perspectives. In A. S. Masten, K. Liebkind, \& D. J. Hernandez (Eds.), Realizing the potential of immigrant youth (pp. 117-158). New York, NY: Cambridge University Press.

Neto, F. (2002). Acculturation strategies among adolescents from immigrant families in Portugal. International Journal of Intercultural Relations, 26, 17-38. doi:10.1016/S0147-1767(01)00036-0

Nguyen, A.-M. D., \& Benet-Martínez, V. (2013). Biculturalism and adjustment: A meta-analysis. Journal of Cross-Cultural Psychology, 44, 122-159. doi:10.1177/0022022111435097

Noels, K. A., Pon, G., \& Clément, R. (1996). Language, identity, and adjustment: The role of linguistic self-confidence in the acculturation process. Jour- nal of Language and Social Psychology, 15, 246-264. doi:10.1177/0261927X960153003

Nystad, K., Spein, A. R., Balto, A. M., \& Ingstad, B. (2017). Ethnic identity negotiation among Sami youth living in a majority Sami community in Norway. International Journal of Circumpolar Health, 76(1), Article 1316939. doi:10.1080/22423982.2017.1316939

Oishi, S., \& Graham, J. (2010). Social ecology: Lost and found in psychological science. Perspectives on Psychological Science, 5, 356-377. doi:10.1177/1745691610374588

Phinney, J. S. (1990). Ethnic identity in adolescents and adults: Review of research. Psychological Bulletin, 108, 499-514.

Rudmin, F. W., \& Ahmadzadeh, V. (2001). Psychometric critique of acculturation psychology: The case of Iranian migrants in Norway. Scandinavian Journal of Psychology, 42, 41-56. doi:10.1111/1467-9450.00213

Ryder, A. G., Alden, L. E., \& Paulhus, D. L. (2000). Is acculturation unidimensional or bidimensional? A headto-head comparison in the prediction of personality, selfidentity, and adjustment. Journal of Personality and Social Psychology, 79, 49-65. doi:10.1037/0022-3514.79.1.49

Ryder, A. G., Ban, L. M., \& Chentsova-Dutton, Y. E. (2011). Towards a cultural-clinical psychology. Social and Personality Psychology Compass, 5, 960-975. doi:10.1111/j.1751-9004.2011.00404.x

Sam, D. L., \& Berry, J. W. (2010). Acculturation: When individuals and groups of different cultural backgrounds meet. Perspectives on Psychological Science, 5, 472-481. doi: $10.1177 / 1745691610373075$

Schachner, M. K., Van de Vijver, F. J. R., \& Noack, P. (2014). Family-related antecedents of early adolescent immigrants' psychological and sociocultural school adjustment in Germany. Journal of Cross- Cultural Psychology, 45, 1606-1625. doi:10.1177/0022022114543831

Schachner, M. K., Van de Vijver, F. J. R., \& Noack, P. (2017). Contextual conditions for acculturation and adjustment of adolescent immigrants-Integrating theory and findings. Online Readings in Psychology and Culture, 8(1) Article 12. doi:10.9707/2307-0919.1142

Schachner, M. K., Van de Vijver, F. J. R., \& Noack, P. (2018). Acculturation and school adjustment of earlyadolescent immigrant boys and girls in Germany: Conditions in school, family, and ethnic group. The Journal of Early Adolescence, 38, 352-384. doi:10.1177/0272431616670991

Syed, M., Juang, L. P., \& Svensson, Y. (2018). Toward a new understanding of ethnic/racial settings for ethnic/racial identity development. Journal of Research on Adolescence, 28, 262-276.

Telzer, E. H. (2010). Expanding the acculturation gapdistress model: An integrative review of research. Human Development, 53, 313-340. doi:10.1159/000322476

Tonsing, K. N. (2014). Acculturation and adapta- 
tion of first- and second-generation South Asians in Hong Kong. International Journal of Social Welfare, 23, 410-420. doi:10.1111/ijsw.12079

Tse, L. (2000). The effects of ethnic identity formation on bilingual maintenance and development: An analysis of Asian American narratives. International Journal of Bilingual Education and Bilingualism, 3, 185-200. doi:10.1080/13670050008667706

Umaña-Taylor, A. J., Alfaro, E. C., Bámaca, M. Y., \& Guimond, A. B. (2009). The central role of familial ethnic socialization in Latino adolescents' cultural orientation. Journal of Marriage and Family, 71, 46-60. doi:10.1111/j.17413737.2008.00579.x

Vallacher, R. R., Read, S. J., \& Nowak, A. (2002). The dynamical perspective in personality and social psychology. Personality and Social Psychology Review, 6, 264-273. doi:10.1207/S15327957PSPR0604_01

Wan, C., \& Chew, Y.-G. (2013). Cultural knowledge, category label, and social connections: Components of cultural identity in the global, multicultural context. Asian Journal of Social Psychology, 16, 247-259. doi:10.1111/ajsp.12029

Ward, C. (2001). The ABCs of acculturation. In D. R. Matsumoto (Ed.), The handbook of culture $\mathcal{E}$ psychology (pp.
411-466). New York, NY: Oxford University Press.

Ward, C., Fox, S., Wilson, J., Stuart, J., \& Kus, L. (2010). Contextual influences on acculturation processes: The roles of family, community and society. Psychological Studies, 55, 26-34. doi:10.1007/s12646-010-0003-8

Ward, C., \& Geeraert, N. (2016). Advancing acculturation theory and research: The acculturation process in its ecological context. Current Opinion in Psychology, 8, 98-104. doi:10.1016/j.copsyc.2015.09.021

Ward, C., \& Kennedy, A. (1993). Where's the "culture" in cross-cultural transition? Comparative studies of sojourner adjustment. Journal of Cross-Cultural Psychology, 24, 221-249.

Ward, C., \& Kennedy, A. (1994). Acculturation strategies, psychological adjustment, and sociocultural competence during cross-cultural transitions. International Journal of Intercultural Relations, 18, 329-343. doi:10.1016/01471767(94)90036-1

Ward, C., \& Kus, L. (2012). Back to and beyond Berry's basics: The conceptualization, operationalization and classification of acculturation. International Journal of Intercultural Relations, 36, 472-485. doi:10.1016/j.ijintrel.2012.02.002 